\title{
O que Sabemos Sobre o Desmame Ventilatório nos Pacientes com TCE?
}

\author{
Clynton Lourenso Correa
}

\begin{abstract}
Fisioterapeuta, Mestre e Doutor em Ciências Morfológicas, Professor Adjunto do Curso de Fisioterapia, Universidade Federal do Rio de Janeiro; Diretor-Científico da Associação Brasileira de Fisioterapia Neurofuncional (ABRAFIN), Rio de Janeiro-RJ, Brasil.
\end{abstract}

Em virtude de um mundo cada vez mais urbanizado e, somado a esse fato, a presença de diferenças econômico-sociais nos países em desenvolvimento, como é o caso do Brasil, observamos um crescente número de pacientes com traumatismo crânio-encefálico (TCE). O TCE é causado, principalmente, por acidentes automobilísticos, atropelamentos, acidentes ciclísticos e motociclísticos, as agressōes físicas, as quedas, as lesōes por arma de fogo, entre outras menos frequentes.

Apesar da importância e impacto para a saúde pública, poucos estudos são conduzidos sobre o TCE, inclusive em países desenvolvidos por dificuldades metodológicas ${ }^{1}$. No Brasil, nos últimos 20 anos, mais de 1 milhão de pessoas tiveram alguma deficiência em virtude de traumas, sendo os acidentes de trânsito os principais responsáveis por essas taxas². No ano de 1993 no Estado de São Paulo, foram constatados 57 mil óbitos decorrentes de TCE. No Hospital das Clínicas da Faculdade de Medicina da Universidade de São Paulo, em um período de 8 meses, foram atendidas 6125 vítimas de TCE: 1054 necessitaram de hospitalizaçâo, 320 de intervençôes neurocirúrgicas e 89 faleceram.

É nesse contexto que a Revista Neurociências apresenta o artigo intitulado "Perfil Clínico e Desmame Ventilatório de Pacientes Acometidos por Traumatismo Crânio-Encefálico"3. Os autores problematizam que muitos dos pacientes com TCE são examinados de urgência, sem serem hospitalizados e muitos pacientes evoluem para complicaçôes neurológicas e/ou psíquicas com insuficiência respiratória com necessidade de intubação traqueal e suporte ventilatório artificial ${ }^{3}$.

Ainda não existem dados clínicos robustos disponíveis na literatura científica que descrevam os eventos relacionados ao insucesso na extubação nessa população $0^{4}$. Nesse sentido, um estudo retrospectivo foi conduzido para elucidar essa questão e constatou-se que 99 pacientes com TCE foram intubados e a maioria desses pacientes (63) necessitou de reintubação em virtude da dificuldade respiratória ou alteraçấo do estado mental. Esses pacientes tiveram, por exemplo, atelectasia e ventilaçăo-minuto diminuída, independente da presença de febre, pneumonia, aspiração e aumento do trabalho respiratórión. A incidência de falha para extubaçáo dos pacientes com TCE no estudo conduzido por pesquisadores norte-americanos foi de $6,1 \%{ }^{4}$, sendo esse valor menor do que os valores encontrados em população geral que necessita de cuidados em UTI (13-18\%).

Pelo exposto acima, a Revista Neurociências traz ao palco científico, uma pergunta pertinente: porque existe insucesso para a extubação (ou desmame ventilatório) nos pacientes com TCE? Os autores do artigo publicado nessa ediçãa ${ }^{3}$ analisaram 73 prontuários de pacientes com diagnóstico de TCE, dos quais $53(72,6 \%)$ tiveram sucesso na evoluçáo e retirada da ventilação mecânica e 20 $(27,4 \%)$ evoluíram para o insucesso do desmame ventilatório. As informaçóes procuradas nos prontuários foram: local e causa do trauma, local do hematoma, modo do desmame ventilatório, níveis de consciência e dados gasométricos. Os autores relatam que $94,5 \%$ dos pacientes eram do sexo masculino, dado que corrobora com os já descritos na literatura ${ }^{5}$. Nesse sentido, também é importante destacar a necessidade de açóes governamentais que extrapolem "as paredes" dos centros de terapia intensiva, ou seja, açôes que possam diminuir efetivamente as causas do TCE, nesse caso, a implementação (ou aprimoramento) de políticas sociais e educativas considerando estudos de gênero uma vez que a populaçáo de pacientes com TCE é majoritariamente masculina e envolve questóes relativas à violência. Nesse aspecto, o (re)conhecimento da raiz causadora do TCE no país é tấo importante quanto o 
combate às consequências advindas dessa doença.

Os referidos autores sugerem que variáveis devem ser consideradas para estabelecer o sucesso ou não do desmame nesses pacientes, a saber: local do trauma e do hematoma, nível de consciência, dados gasométricos, implementação de estratégias sistemáticas para escolha dos pacientes para o teste de respiração espontânea e o método de extubação a ser utilizado. Contudo, os autores não evidenciam no texto os parâmetros e critérios utilizados para determinar a insuficiência respiratória nesses pacientes, tais como: frequência respiratória, $\mathrm{PaCO}_{2}, \mathrm{PaO}_{2}, \mathrm{SaO}_{2}$, mas discutem a dificuldade de encontrar nos prontuários analisados tais informaçôes. Essa consideraçáo dos referidos autores aponta para uma questáo importante e crucial na práxis dos profissionais neurointensivistas: existe um protocolo ou fluxograma de tomada de decisóes para determinar o momento apropriado de extubação dos pacientes com TCE? Portanto, é importante ser pensado e, subsequentemente, estabelecida a tomada de decisão para o melhor momento de extubação de pacientes com TCE considerando as variáveis supra-citadas.

Outras questóes importantes surgem a partir dos resultados do estudo, a saber: 1) No grupo de insucesso do desmame, qual foi o tempo de reintubação? 2) Existem diferenças em pacientes que necessitam da reintubação em tempos diferentes na pós-extubação, por exemplo, 24, 48 ou 72h? 3) Quais razóes podem ser atribuídas a esse fato? 4) Existe algum fator preditor para a reintubação precoce ou tardia? Qual(is) o(s) parâmetro(s) utilizado(s) para estabelecer o insucesso para a extubação?

\section{REFERÊNCIAS}

1.Koizume MS, Lebrão ML, Mello-Jorge MHP, Primerano V. Morbimortalidade por traumatismo crânio-encefálico no município de São Paulo, 1997. Arq Neuropsiquiatr 2000;58:1-13.

2.Andrade AF, Manreza LA, Giudicissi M Filho, Miura FK. Normas de atendimento ao paciente com traumatismo crânio-encefálico. Temas Atuais em Neurocirurgia 1996;2:1-22.

3.Lima MVC, Guimarães RMO, Silva GPF, Mont'Alverne DGB. Perfil Clínico e Desmame Ventilatório de Pacientes Acometidos por Traumatismo Crânio-Encefálico. Rev Neurocienc 2012;20(3):354-9.

4.Karanjia N, Nordquist D, Stevens R, Nyquist P. A clinical description of extubation failure in patients with primary brain injury. Neurocrit Care 2011;15(1):4-12.

http://dx.doi.org/10.1007/s12028-011-9528-5

5.Melo JRT, da Silva RA, Jr EDM. Características dos pacientes com trauma cranioencefálico na cidade de Salvador, Bahia, Brasil. Arq Neuropsiquiatr 2004;62(3A):711-715.

http://dx.doi.org/10.1590/S0004-282X2004000400027 